Brit. J. Ophthal. (1965) 49, 516

\title{
HYPERPLASIA OF THE ANTERIOR LAYER OF THE IRIS STROMA*†
}

\author{
BY \\ MALCOLM N. LUXENBERG \\ From the Bascom Palmer Eye Institute, Department of Ophthalmology, \\ University of Miami School of Medicine, Miami, Florida
}

THE purpose of this report is to present the clinical and histopathological findings in a case of marked bilateral persistence of the anterior portion of the foetal vascular system. A brief review of the embryogenesis of the lesion is presented with photographic correlation of the clinical and pathological findings.

\section{Case Report}

A 51-year-old Negro male developed painless progressive loss of vision in both eyes in the course of one month. There was no history of previous eye disease or injuries. The patient's vision was previously normal. General examination and past medical history yielded no information. No family history was available.

Examination.-The visual acuity was hand movements in each eye, with left exotropia. The visual fields were full to light projection. Slit-lamp examination revealed a few fine white punctate opacities centrally in the left cornea at the level of Bowman's membrane or anterior stroma. A few areas of brownish pigmentation were present on the corneal endothelium nasally in the right eye and temporally in the left eye. The anterior chamber was of normal depth. Arising from the iris surface in the region of the collarette in both eyes was a projection of the iris stroma in an anterior and central direction. This produced a pseudopupil just anterior to but separated from the normal pupil (Figs 1 and 2). It was not attached to the lens at any point, and was non-

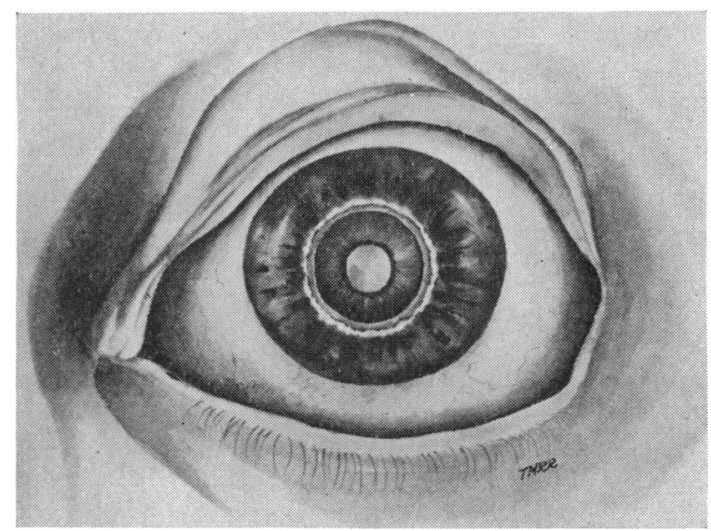

FIG. 1.-Drawing of iris anomaly.

* Received for publication December 21,1964 .
$\dagger$ This work was supported in part by the Florida Lions Eye Bank District 35A. 


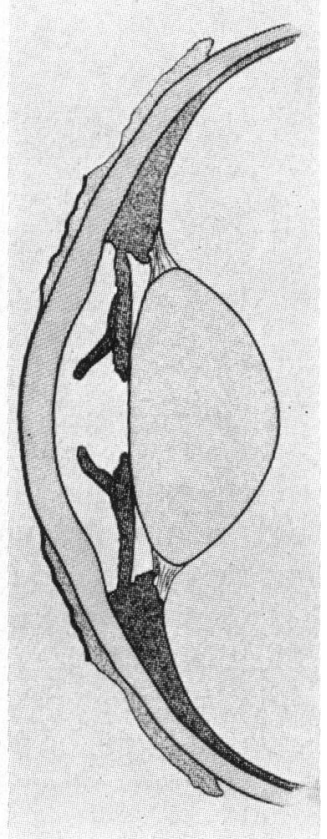

FIG. 2.-Schematic representation of iris anomaly.

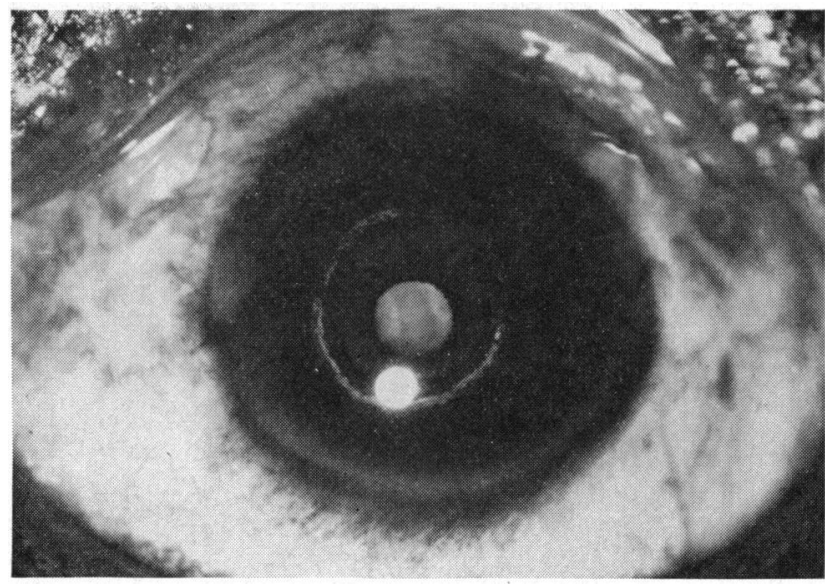

FIG. 3.-External photograph with true pupil constricted.

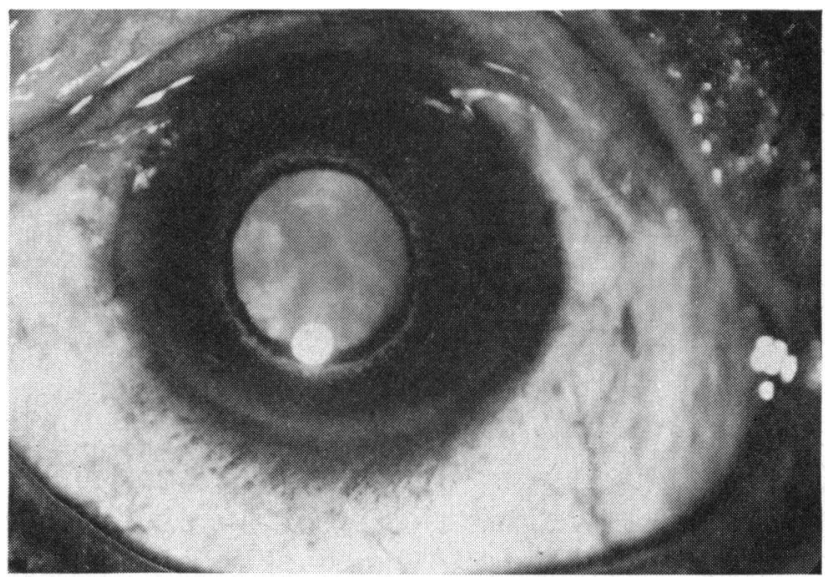

Fig. 4.-External photograph with true pupil dilated.

contractile, approximately $5 \mathrm{~mm}$. in diameter, with a thin white irregular band of tissue at its margin. The true pupil demonstrated normal responses to light and convergence (Figs 3 and 4). Densely cataractous lenses prevented visualization of the fundi. The patient was admitted to the hospital for cataract extraction. Routine laboratory studies were all within normal limits.

Treatment.-A lens extraction was performed on the left eye. A full iridectomy was used because the pseudopupil would not dilate. There were no complications and the postoperative course was uneventful. Four days later the right lens was removed in a similar manner, and again the postoperative course was uneventful.

Two months after surgery the visual acuity in the right and left eyes was correctable to 20/30 and 20/25 respectively. Gonioscopic and fundus examinations at that time revealed no abnormalities.

Histopathology (Fig. 5).-At the level of the collarette there was an abnormal continuation of a hyperplastic anterior layer of the iris stroma which projected anterior to, and was separated from, the pupillary portion of the iris. This hyperplastic tissue consisted of connective tissue, uveal melanocytes, and small thick-walled blood vessels. The pupillary portion of the iris was normal. 


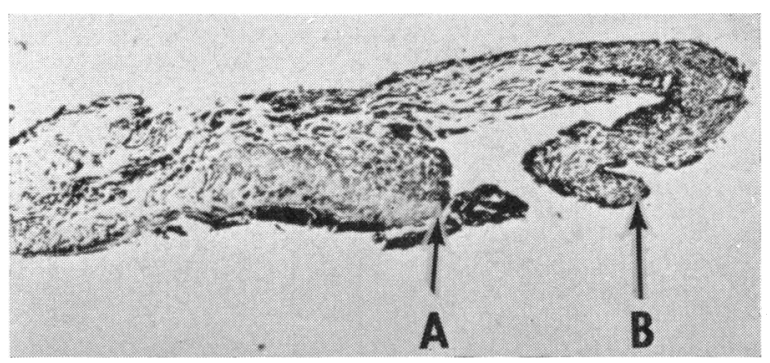

Fig. 5.-Microscopic section of iris lesion with pupil dilated. (Trichrome $\times 30$.)

A.-Margin of true pupil. B.-Margin of pseudopupil.

\section{Discussion}

The clinical and histological appearance of the iris lesion in this case suggests that it results from hyperplasia of the anterior layer of the iris stroma probably in association with aberration in the atrophy of the tunica vasculosa lentis. The precursor of the anterior leaf of the iris stroma is the anterior portion of the tunica vasculosa lentis which begins to form at about the 17-25 mm. stage (Duke-Elder, 1963; Mann, 1949). It is composed of vascular tissue with accompanying mesoderm which grows out from the annular vessel between the lens and the already formed mesoderm of the cornea. It is thicker in the periphery where it persists as the anterior layer of the iris stroma and becomes very thin centrally to form the pupillary membrane. In this central area the anterior portion of the tunica vasculosa lentis is composed of several arcades of thin-walled vessels which contain a layer of mesoderm between them. These arcades grow centrally to cover almost the entire pupil during the fourth and fifth months. In the sixth month the most central arcades begin to atrophy and this process continues through the ninth month until all the arcades have atrophied except for the first one which persists as the minor vascular circle of the iris. When these arcades fail to atrophy they present clinically as persistence of the pupillary membrane which may take any of several forms. During the third month of development $(65-70 \mathrm{~mm}$. stage) the foremost portion of the optic cup is undergoing rapid growth and the mesoderm situated at its rim grows inward between the anterior surface of the lens and the anterior or vascular layer of the iris stroma to form the posterior stromal layer of the iris (Fig. 6).

This report concerns a closely related abnormality in which the peripheral portion of the anterior leaf of the iris stroma becomes hyperplastic and does not terminate at the collarette as it normally does but continues to grow over the pupil. DukeElder (1964a) refers to this as hyperplasia of the anterior layer of the iris stroma or accessory iris membrane.

Differentiation of these aberrations of development from inflammatory residua should be considered. The latter usually arise from or have connexions with the pupillary margin, whereas the former arise from the collarette.

Persistence of the foetal vascular system, especially remnants of the anterior portion of the tunica vasculosa lentis, has been frequently reported in the literature. The first detailed report was by Weber (1861) and other descriptions have appeared 


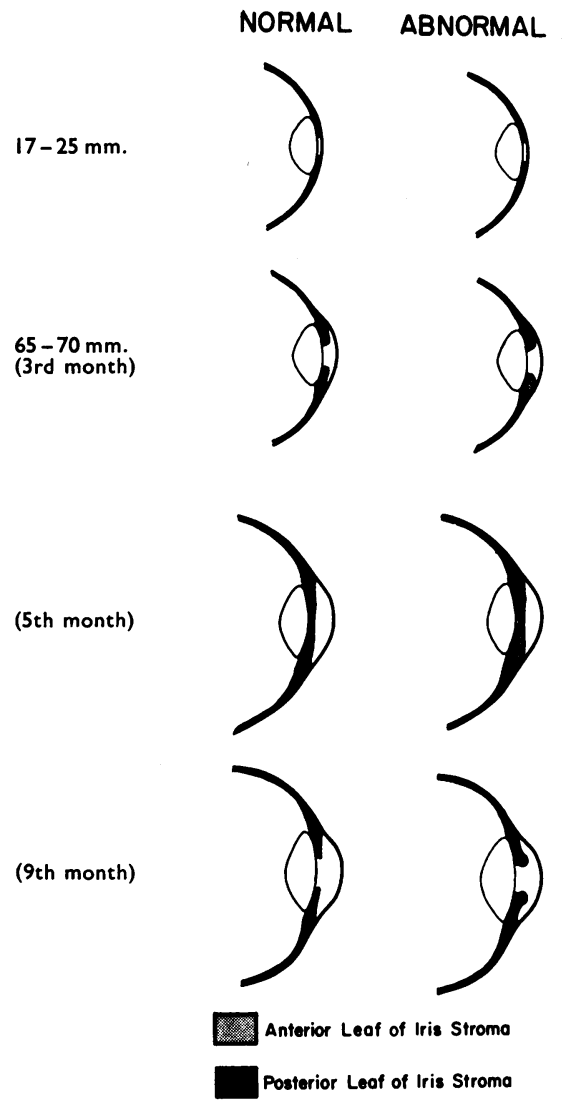

Fig. 6.-Normal and abnormal iris development.

since that time (Graefe, 1865; von Szily, 1909; Wiegmann, 1913; Cassady and Light, 1957; Levy, 1957; de Almeida, 1961; Mann, 1957; Duke-Elder, 1964b). However, none of these articles contains good photomicrographs of the pathology of the lesion or photographs demonstrating the immobility of the hyperplastic iris stroma. Both of these studies have been obtained in this patient, and it is felt that this warrants the reporting of the case. Duke-Elder (1964c) reports that various authors have noted persistence of the pupillary membrane in from 30 to 95 per cent. of the population usually occurring in a mild form with only one or two strands. The incidence is much greater in the newborn with a tendency for the remnants to atrophy during the first year. Any part of the membrane still present at the end of that time tends to persist permanently. Only rarely does abnormal development or persistence of the anterior portion of the tunica vasculosa lentis reach the proportions demonstrated in this case.

Treatment is seldom necessary as these remnants rarely interfere with vision. However, when they do exist in a more complete form and obstruct the pupillary aperture, a coreoplasty may be required (Levy, 1957). 


\section{Summary}

The clinical and histopathological findings in a patient with bilateral hyperplasia of the anterior layer of the iris stroma are presented. The embryogenesis of the iris lesion is discussed.

\section{REFERENCES}

Almeida, A. M. DE (1961). Arch. bras. Oftal., 24, 15.

Cassady, J. R., and Light, A. (1957). A.M.A. Arch. Ophthal., 58, 438.

DUKE-ELDER, SiR S. (1963). "System of Ophthalmology", vol. 3, pt 1, pp. 159, 190. Kimpton, London. 1964a). Ibid., vol. 3, pt. 2, p. 587. (1964b). Ibid., p. 587, 775. (1964c). Ibid., p. 776.

Graefe, A. (1865). v. Graefes Arch Ophthal, 11, pt 1, p. 209.

LEVY, W. J. (1957). Brit. J. Ophthal., 41, 120.

MANN, I. (1949). "The Development of the Human Eye", 2nd ed., pp. 204, 214. B.M.A., London. (1957). "Developmental Abnormalities of the Eye", 2nd ed., p. 261. B.M.A., London.

SzILY, A. von (1909). Klin. Mbl. Augenheilk., 47 (N.s. 7), 369.

WEBER, A. (1861). v. Graefes Arch. Ophthal., 8, pt 1, p. 337.

Wiegmann, E. (1913). Klin. Mbl. Augenheilk., 51 (N.s. 16), 697. 